\title{
Chuvas em Santa Catarina durante eventos do EI Niño oscilação sul
}

Rosandro Boligon Minuzzi*

\section{Resumo}

Dados diários de 25 estações pluviométricas de 1960 a 2004, foram utilizados com o propósito de analisar a influência do El Niño Oscilação Sul no comportamento da chuva em Santa Catarina. A quantidade de chuva mensal (setembro a maio) foi classificada e correlacionada com a temperatura da superfície do mar (TSM) de regiões do Pacífico Equatorial. Durante a La Niña, a quantidade de chuva em outubro e novembro ficam abaixo da média, ocorrendo comportamento oposto, em abril e maio. Em anos de El Niño as chuvas de setembro ficam abaixo da média climática no Litoral de Santa Catarina. Em contrapartida, em novembro, no verão e no mês de maio, tendem a ser períodos 'chuvosos'. As chuvas dos meses com o maior número de desvios (novembro e maio), estão correlacionadas com o comportamento da TSM nas regiões do Pacífico Equatorial.

Palavras-chave: El Niño; La Niña; Clima.

Rainfall in Santa Catarina during the El Niño southern oscillation events

\section{Abstract}

Daily data from 25 pluviometric stations from 1960 to 2004, were used in order to analyze the influence of the El Niño Southern Oscillation on the behavior of rainfall in Santa Catarina. The amount of monthly rainfall (September-May) was classified and

* Professor Doutor do ENR-CCA/UFSC (rbminuzzi@cca.ufsc.br).

Geosul, Florianópolis, v. 25, n. 50, p 107-127, jul./dez. 2010 
MINUZZI, R.B. Chuvas em Santa Catarina durante eventos do El Niño ...

correlated with the sea surface temperature (SST) of areas of Equatorial Pacific. During La Niña, the amount of rainfall in October and November are below average, with opposite behavior, in April and May. In the years of El Niño rainfalls in September are below average in the Coast in Santa Catarina. However, in November, in summer in month of May, periods tend to be 'rainy'. The rainfall of the months with the largest number of deviations (November-May), are related to the behavior of the SST in the regions of the Equatorial Pacific.

Key words: El Niño; La Niña; Climate.

\section{Introdução}

Dentre as forçantes climáticas de grande escala oriundas dos oceanos, o El Niño Oscilação Sul (ENOS) está entre as mais estudadas. A extensão da região no Pacífico Equatorial onde ocorrem as anomalias da temperatura da superfície do mar (TSM) e a grande capacidade da água em transportar energia, faz com que a forçante climática provoque mudanças no padrão normal da circulação atmosférica. Por isso, a ocorrência do ENOS é vista como agente de anomalias climáticas em várias regiões do globo, principalmente na precipitação e, por conseqüência, afetando diversos setores da sociedade e da economia. A variação irregular e a persistência em torno das condições normais da temperatura do Pacífico Equatorial revelam duas fases opostas do ENOS. Um desses extremos é representado pelas condições de El Niño, quando se verifica um aquecimento das águas (também denominada fase quente), e a situação oposta, ou seja, quando se verifica um resfriamento das águas (também denominada fase fria), representa condições de La Niña. No contexto geral, as anomalias climáticas relacionadas ao El Niño e La Niña ocorrem nas mesmas regiões, mas de maneiras opostas. Porém, Manson e Goddard (2001) chamaram a atenção para um exagero em relação à influência do ENOS no regime de precipitação, pois somente cerca 
MINUZZI, R.B. Chuvas em Santa Catarina durante eventos do El Niño ...

de $20 \%$ a $30 \%$ das áreas continentais utilizadas no estudo tiveram probabilidades significativas de precipitação sazonal acima da média, ao menos durante parte do ano. Considerando que várias áreas são afetadas em diferentes períodos do ano, a fração de áreas afetadas em qualquer período particular foi somente de $15 \%$ a 25\%. As respostas das fases do ENOS em muitas áreas nem sempre são contrárias, e os eventos de La Niña afetam 5 a $15 \%$ mais áreas continentais do que durante eventos El Niño.

Ressalta-se que além de ter o conhecimento do regime pluviométrico durante eventos do ENOS, é importante analisar se tais efeitos possuem relação com a forçante climática. A literatura indica grande número de estudos enfatizando a relação entre as anomalias da TSM do Pacífico com o clima em várias partes do mundo. Grimm e Tedeschi (2004) relataram que em episódios El Niño, o número de eventos extremos de precipitação tende a aumentar no Centro-Sudeste do Brasil durante a primavera. Enquanto para eventos La Niña eles notaram um comportamento oposto na região, especialmente em outubro e novembro do ano de início da forçante climática, ocorrendo diminuição expressiva em janeiro no número de eventos extremos. Gershunov e Barnett (1998) e Cayan et al. (1999) mostraram que nos Estados Unidos a influência do ENOS na chuva diária é maior sobre os eventos extremos do que nos eventos de chuva fraca e moderada.

Assim, diante destas considerações, este estudo visa analisar o regime da chuva mensal no estado de Santa Catarina, em anos do ENOS, e a relação existente desta variável meteorológica com a TSM do Pacífico Equatorial.

\section{Material e métodos}

Para o desenvolvimento deste trabalho foram utilizados dados pluviométricos de 25 estações localizadas no Estado de Santa Catarina (Figura 1) e pertencentes à Rede Hidrometeorológica da Agência Nacional de Águas (ANA). Os valores mensais médios da Temperatura da Superfície do Mar 
MINUZZI, R.B. Chuvas em Santa Catarina durante eventos do El Niño ...

(TSM) das quatro regiões Niños (Figura 2), no período de 1982 a 2004 (resolução espacial de $1^{\circ} \times 1^{\circ}$ ), a serem utilizadas no software Climate Predictability Tool (CPT) e do período de 1960 a 2008, para a definição da cronologia do ENOS, foram obtidos na base de dados do International Research Institute for Climate Prediction (IRI, 2008). Em razão da ausência de estações com série histórica o suficiente para o estudo, as regiões climáticas ' $1 B$ ' e ' 5 ' não foram envolvidas nas análises.

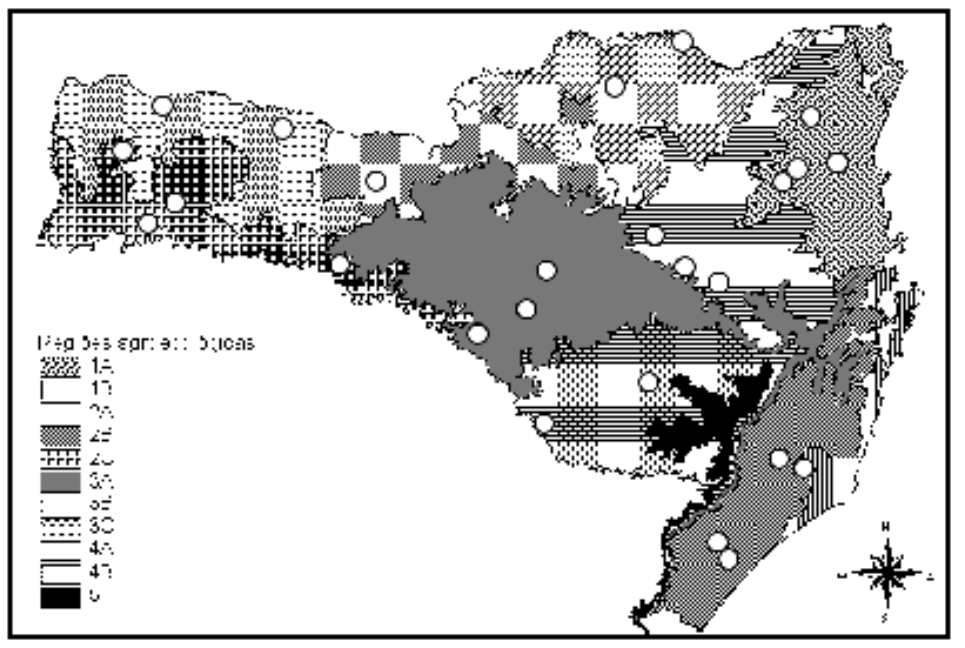

FIGURA 1: Localização das estações pluviométricas em regiões climaticamente homogêneas do estado de Santa Catarina (BRAGA e GHELLRE, 1999).

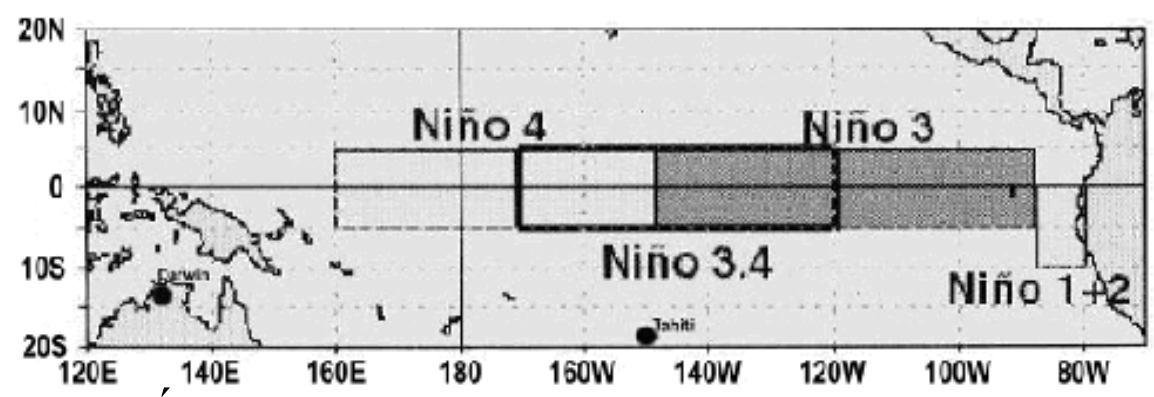

FIGURA 2: Áreas no oceano Pacífico Equatorial conhecidas como Niño 1+2, Niño 3, Niño 3.4 e Niño 4 (OLIVEIRA, 1999).

Para o emprego da cronologia de eventos do ciclo El Niño e La Niña (LN), foi realizada uma análise crítica das notações 
MINUZZI, R.B. Chuvas em Santa Catarina durante eventos do El Niño ...

empregadas por vários autores, para evitar que os resultados fossem incoerentes. Foram considerados somente eventos La Niña e El Niño de moderada e forte intensidades no período de 1960 a 2004, sendo os eventos de fraca intensidade, considerados anos neutros. Assim, as classificações referentes a cronologia do El Niño Oscilação Sul - ENOS (Tabela 1) foram baseadas através da TSM da região Niño 3.4, que considera a ocorrência do fenômeno climático quando a média móvel de 5 meses da anomalia de TSM da região oceânica, ultrapassa $0,4^{\circ} \mathrm{C}$ em seis ou mais meses (TRENBERTH, 1997). Referente à intensidade dos eventos, a melhor definição seria basear-se na extensão e temperatura média das águas no Pacífico equatorial com anomalias positivas (nos anos EN) ou negativas (nos anos LN), além de outras considerações baseadas em outros campos, como pressão, fluxos de vento, radiação de onda longa, dentre outros. Porém, uma questão de ordem prática é que tal sistemática dificilmente pode ser levada para um passado não muito remoto, devido à inexistência de informações detalhadas nesse passado sobre os campos das citadas variáveis meteorológicas (XAVIER, 2001).

TABELA 1: Cronologia de ocorrências do El Niño e da La Niña de intensidades moderada $(\mathrm{M})$ e forte $(\mathrm{F})$

\begin{tabular}{lllll}
\hline El & $2002 / 03(\mathrm{M}) ; 1997 / 98(\mathrm{~F}) ; 1994 / 95(\mathrm{M}) ; 1992 / 93(\mathrm{M}) ;$ \\
Niño & $1991 / 92(\mathrm{~F}) ; 1987 / 88(\mathrm{~F}) ; 1986 / 87(\mathrm{~F}) ; 1982 / 83(\mathrm{~F}) ;$ \\
& $1972 / 73(\mathrm{~F}) ; 1969 / 70(\mathrm{M}) ; 1965 / 66(\mathrm{M})$ & & \\
\hline La & $1999 / 00(\mathrm{~F}) ; 1998 / 99(\mathrm{~F}) ; 1988 / 89(\mathrm{~F}) ; 1975 / 76(\mathrm{~F}) ;$ \\
Niña & $1973 / 74(\mathrm{~F}) ; 1970 / 71(\mathrm{~F}) ; 1964 / 65(\mathrm{M})$ & & \\
\hline
\end{tabular}

A influência do ENOS na chuva mensal (setembro a maio) foi analisada a partir da distribuição dos desvios normalizados (D), obtida pelo valor médio de chuva das estações localizadas numa mesma região climática de Santa Catarina, da série contendo somente os anos do ENOS (X) com a série contendo somente os anos neutros $(\mathrm{U})$, conforme equação 1 , inserindo os períodos 
MINUZZI, R.B. Chuvas em Santa Catarina durante eventos do El Niño ...

temporais (meses) nas seguintes classificações: Muito Chuvoso: D $\geq 40 \%$; Chuvoso: $40 \%>\mathrm{D} \geq 20 \%$; Normal: 20\%> D >-20\%; Seco: $20 \% \geq \mathrm{D}>-40 \%$; e Muito Seco: $\mathrm{D} \leq-40 \%$.

$$
\mathrm{D}=\frac{(\mathrm{X}-\mathrm{U})}{\sqrt{\frac{\mathrm{s}}{\mathrm{n}_{\mathrm{x}}}+\frac{1}{\mathrm{n}_{\mathrm{u}}}}} .100 \%
$$

em que:

$\mathrm{X}=$ valor médio da série em estudo (ENOS);

$\mathrm{U}=$ valor médio da série de referência (anos neutros);

$\mathrm{n}_{\mathrm{x}}=$ número de dados da série em estudo (ENOS);

$\mathrm{n}_{\mathrm{u}}=$ número de dados da série de referência (anos neutros);

$\mathrm{s}=$ desvio-padrão ponderado, obtido por meio de:

$$
\mathrm{s}=\sqrt{\frac{\left(\mathrm{n}_{\mathrm{x}}-1\right) \cdot \mathrm{S}_{\mathrm{x}}^{2}+\left(\mathrm{n}_{\mathrm{u}}-1\right) \cdot \mathrm{S}_{\mathrm{u}}^{2}}{\mathrm{n}_{\mathrm{x}}+\mathrm{n}_{\mathrm{u}}-2}}
$$

sendo $S_{x}^{2}$ e $S_{u}^{2}$ as variâncias da série em estudo (ENOS) e da série de referência (anos neutros), respectivamente.

O período de junho a agosto não foi incluído no estudo, por se tratar de um período que de uma maneira geral, envolve o início e o final de um evento ENOS ou a transição de ocorrência de ambas fases do fenômeno climático.

O grau da correlação existente entre a TSM (variável independente) de cada região Niño (Figura 2) e a precipitação média mensal (variável dependente) de cada região agroecológica de Santa Catarina, foi definida pelos coeficientes de Correlação de Pearson (WILKS, 2006), para diferentes intervalos de tempo (lags), sendo $\mathrm{k}=$ 1, 2 e 3 meses de TSM, antes da precipitação de cada mês. Como exemplo, para definir a correlação da precipitação de dezembro de uma dada região agroecológica, se mantém fixo o valor desta variável meteorológica e realiza-se em separado, a sua correlação com a TSM de novembro (lag 1), de outubro (lag 2) e de setembro (lag 3). Esta metodologia considera que nem sempre a resposta de uma variável meteorológica como a precipitação, pode ser imediata a uma mudança 
MINUZZI, R.B. Chuvas em Santa Catarina durante eventos do El Niño ...

no comportamento da TSM do Pacífico. As regressões foram testadas aos níveis de 5\% e 1\% de significância utilizando o 'valor-p'. Para a execução das referidas análises estatísticas foi utilizado o software Climate Predictability Tool (CPT), desenvolvido pelo IRI (International Research Institute for Climate Prediction).

\section{Resultados e discussões}

\section{El Niño}

A Figura 3 apresenta as classificações da chuva mensal durante eventos El Niño de moderada e forte intensidade. Exceto em setembro, que observa-se uma tendência de chuvas abaixo da climatologia no litoral catarinense (Figura 3a), nos demais meses, há uma tendência de chuvas entre e média climática e acima desta, principalmente, em novembro (Figura 3c), janeiro (Figura 3e), fevereiro (Figura 3f) e maio (Figura 3i), sendo este último, envolvendo quase todo o estado e alcançando a classificação 'muito chuvosa' na região 4A, que envolve a Serra Catarinense. Algumas hipóteses podem ser destacadas para as referidas tendências da chuva, como a sua associação com a maior frequência de sistemas frontais em relação a anos neutros e de La Niña, resultando num aumento de dias com chuvas intensas (FEDOROVA et al., 2007) e a um aumento da frequência do Jato de Baixos Níveis (JBN) sobre a América do Sul (SILVA, 2005), favorecendo o transporte de umidade do Atlântico Norte e da Bacia Amazônica até o Sul e Sudeste do Brasil, especialmente durante o verão (MARENGO et al., 2004). Considerando a associação dessas referidas condições sinóticas com a formação de Complexos Convectivos de Mesoescala (CCMs), pode-se aferir uma possível influência do El Niño na frequência e intensidade do CCM, já que, esse sistema meteorológico ocorre, principalmente na primavera e verão e responde por grande parte na quantidade total de chuva e na sua intensidade (GRIMM, 2009). Por sua vez, eventos do El Niño são apontados como causadores do aumento no número de chuvas intensas (FEDOROVA et al., 2007; GRIMM e TEDESCHI, 2004). 
MINUZZI, R.B. Chuvas em Santa Catarina durante eventos do El Niño ...
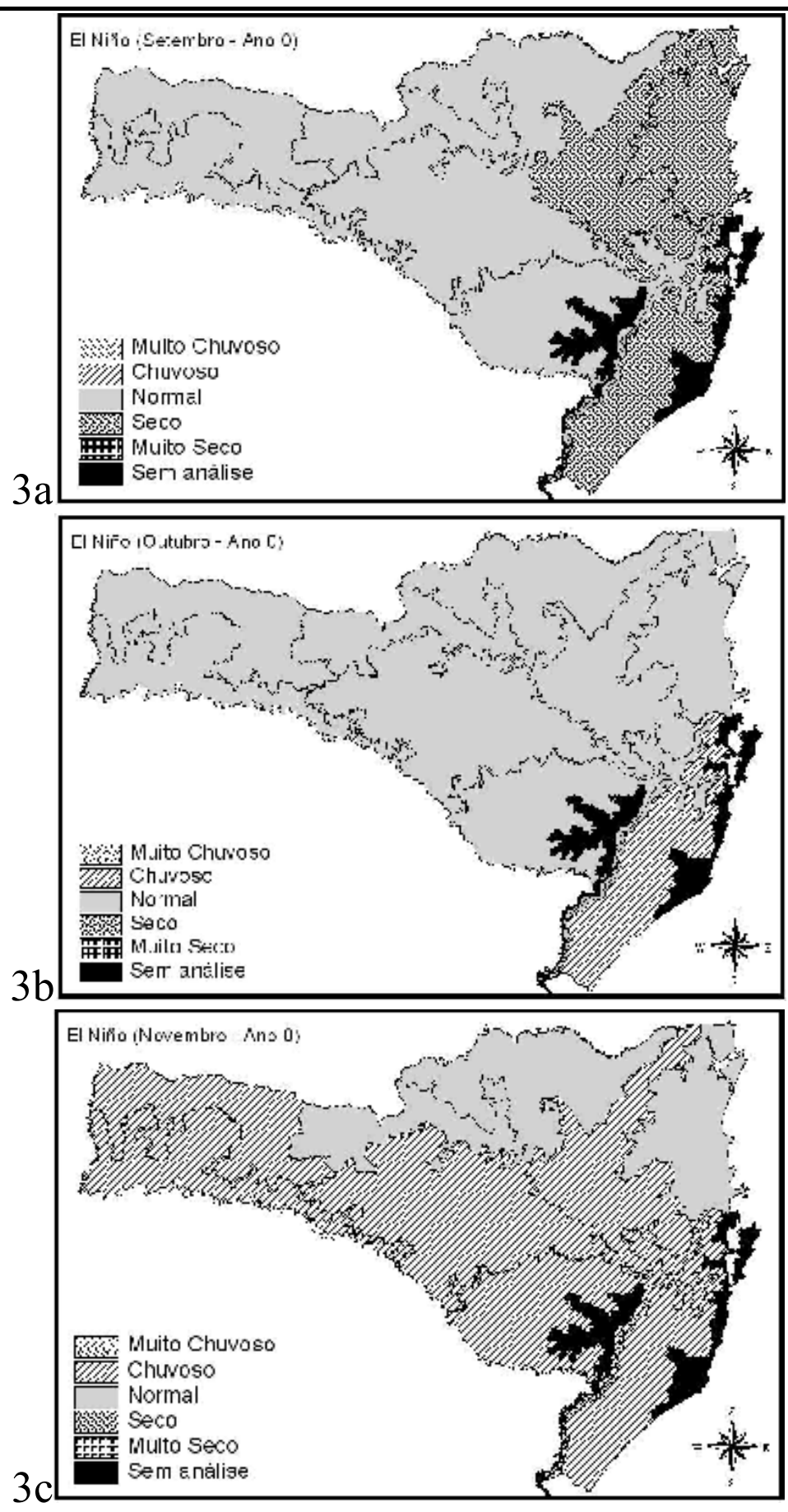
MINUZZI, R.B. Chuvas em Santa Catarina durante eventos do El Niño ...
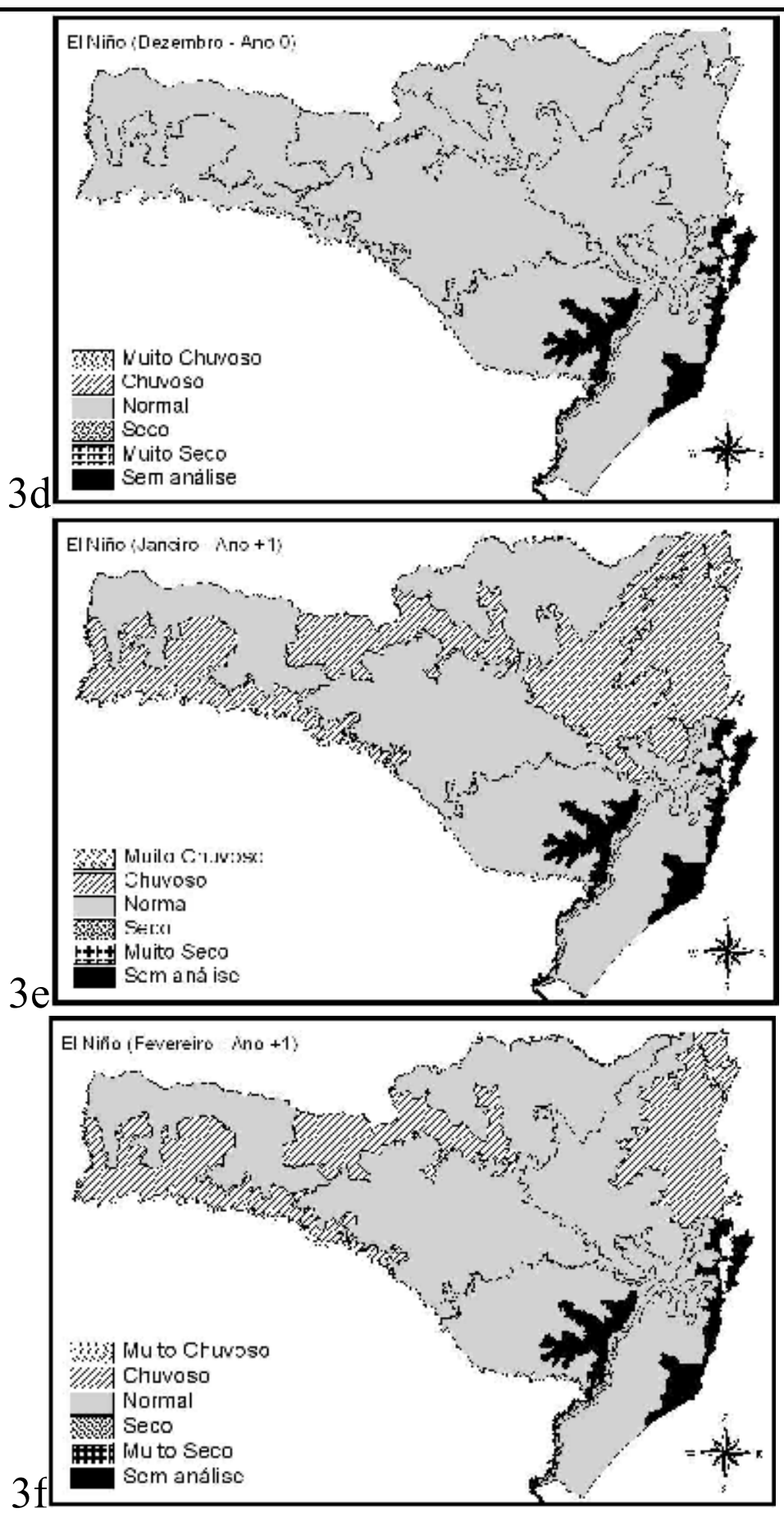

Geosul, v.25, n.50, 2010 
MINUZZI, R.B. Chuvas em Santa Catarina durante eventos do El Niño ...
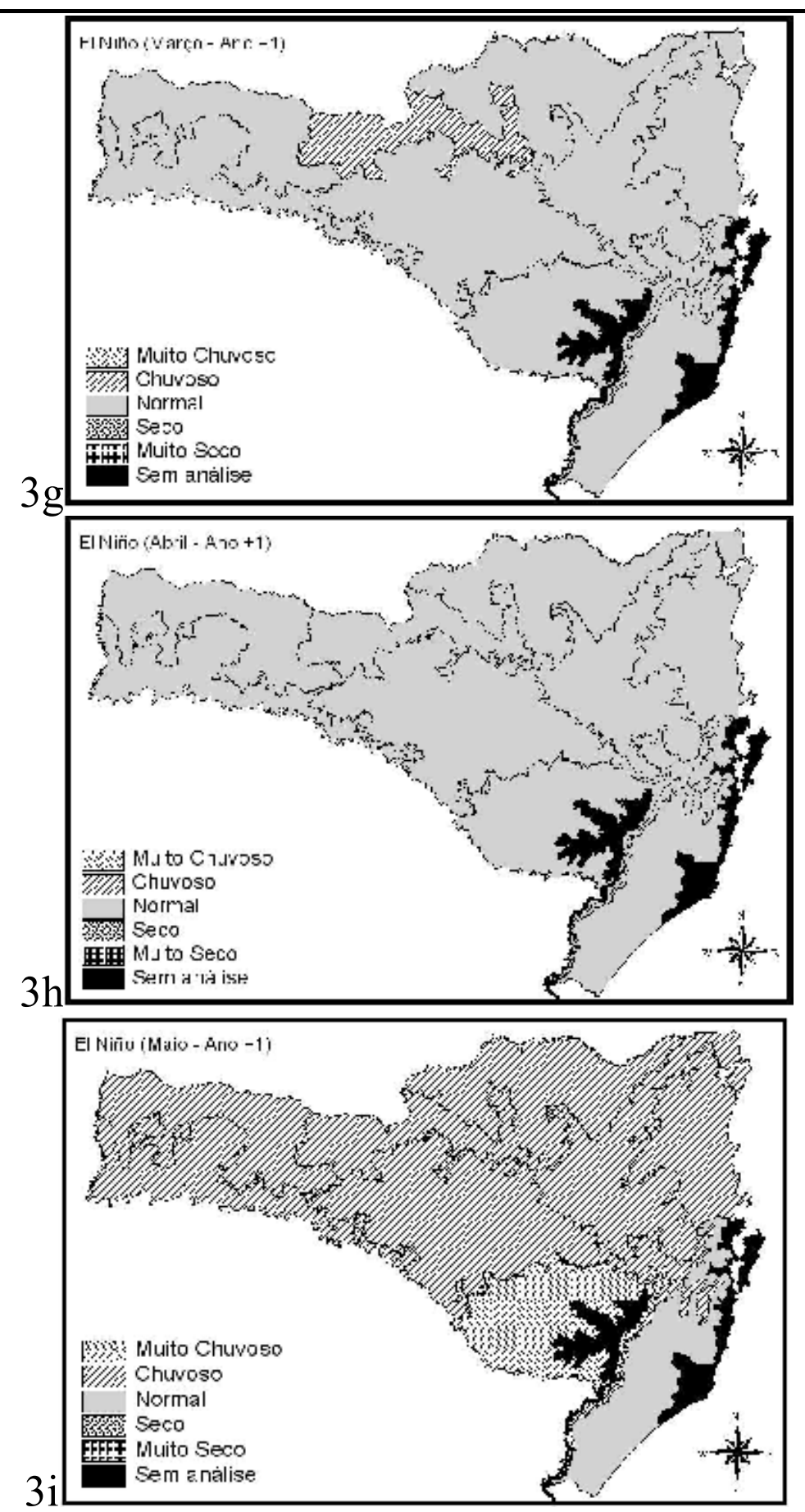

FIGURA 3: Classificações da chuva durante ocorrências do El Niño nos meses de setembro (3a), outubro (3b), novembro (3c), dezembro (3d), janeiro (3e), fevereiro (3f), março (3g), abril (3h) e maio (3i), em regiões climáticas de Santa Catarina. 
MINUZZI, R.B. Chuvas em Santa Catarina durante eventos do El Niño ...

\section{La Niña}

As informações apresentadas na Figura 4 mostram as classificações da chuva mensal durante a ocorrência do evento La Niña. Em outubro e em novembro, há uma tendência de chuvas com valores abaixo da 'normal' climatológica. Chama a atenção o comportamento de novembro que, além das chuvas abaixo da média envolver todo o estado, em grande parte dele, os desvios normalizados alcançam a classificação 'Muito seco'. No ano seguinte ao início do fenômeno climático $($ ano +1$)$, a tendência passa a ser de chuvas acima da média climatologia, apesar dos desvios não serem tão abrangentes e extremos, quanto ao observado no comportamento oposto, previamente destacado para o mês de novembro. Grimm e Ferraz (1998) em uma análise mais abrangente, destacam que em anos La Niña a região Sul do Brasil apresenta anomalias negativas na primavera do ano de início do evento e positivas no ano seguinte. Esta diferença no comportamento sazonal das chuvas em anos La Niña, mostra a importância em realizar análise em escalas temporais menores. Isto deve-se, porque no total de chuva anual, Grimm (2009) mostra que o ENOS sendo a principal fonte de variabilidade interanual do clima no Brasil, apresenta durante a La Niña, anomalias negativas sobre o Sul do Brasil.

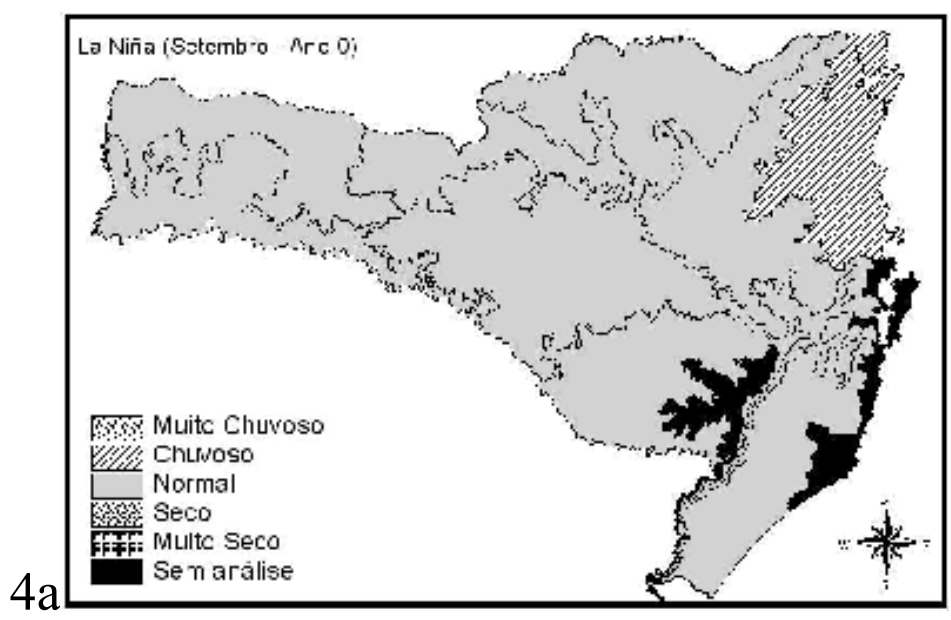


MINUZZI, R.B. Chuvas em Santa Catarina durante eventos do El Niño ...
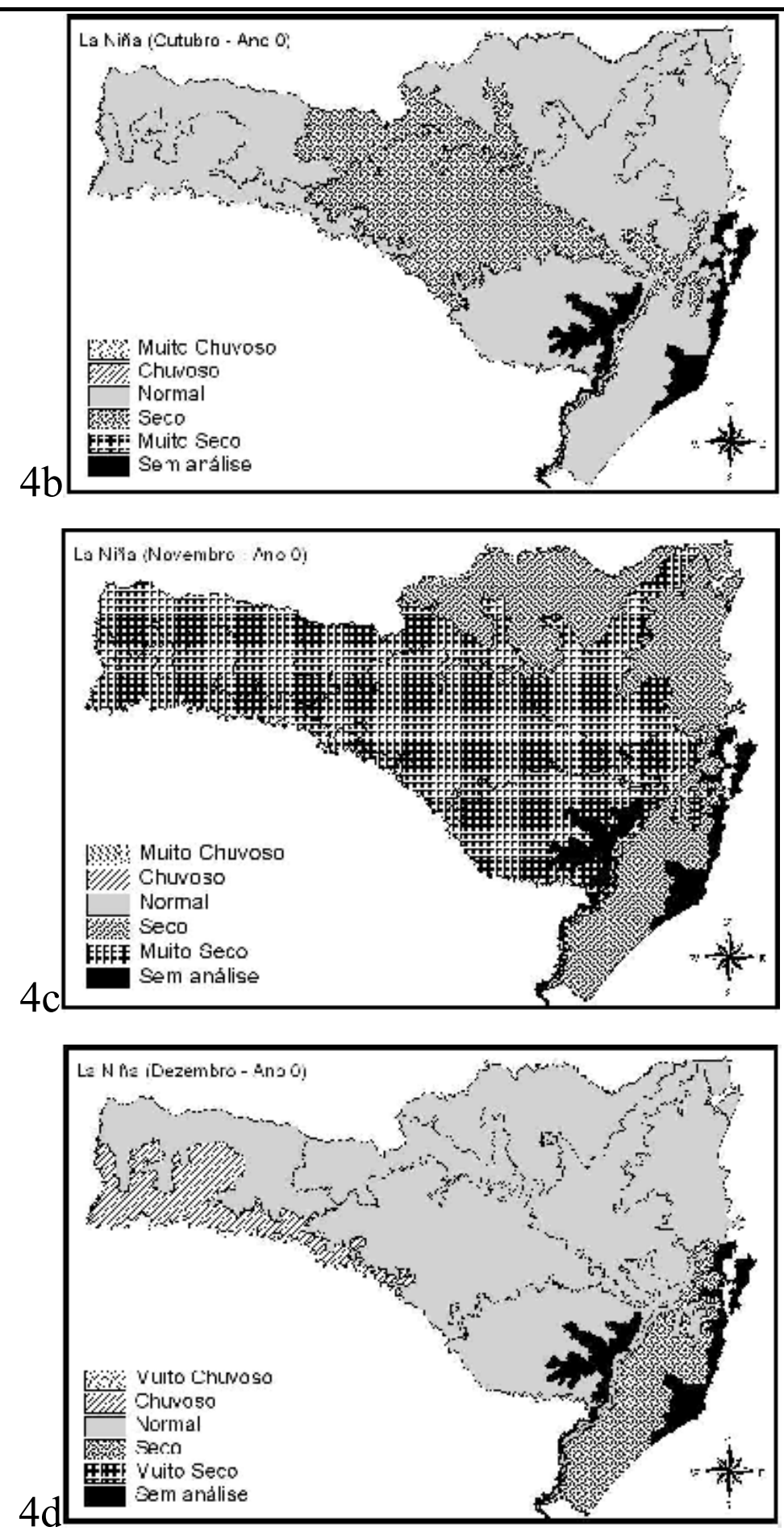
MINUZZI, R.B. Chuvas em Santa Catarina durante eventos do El Niño ...
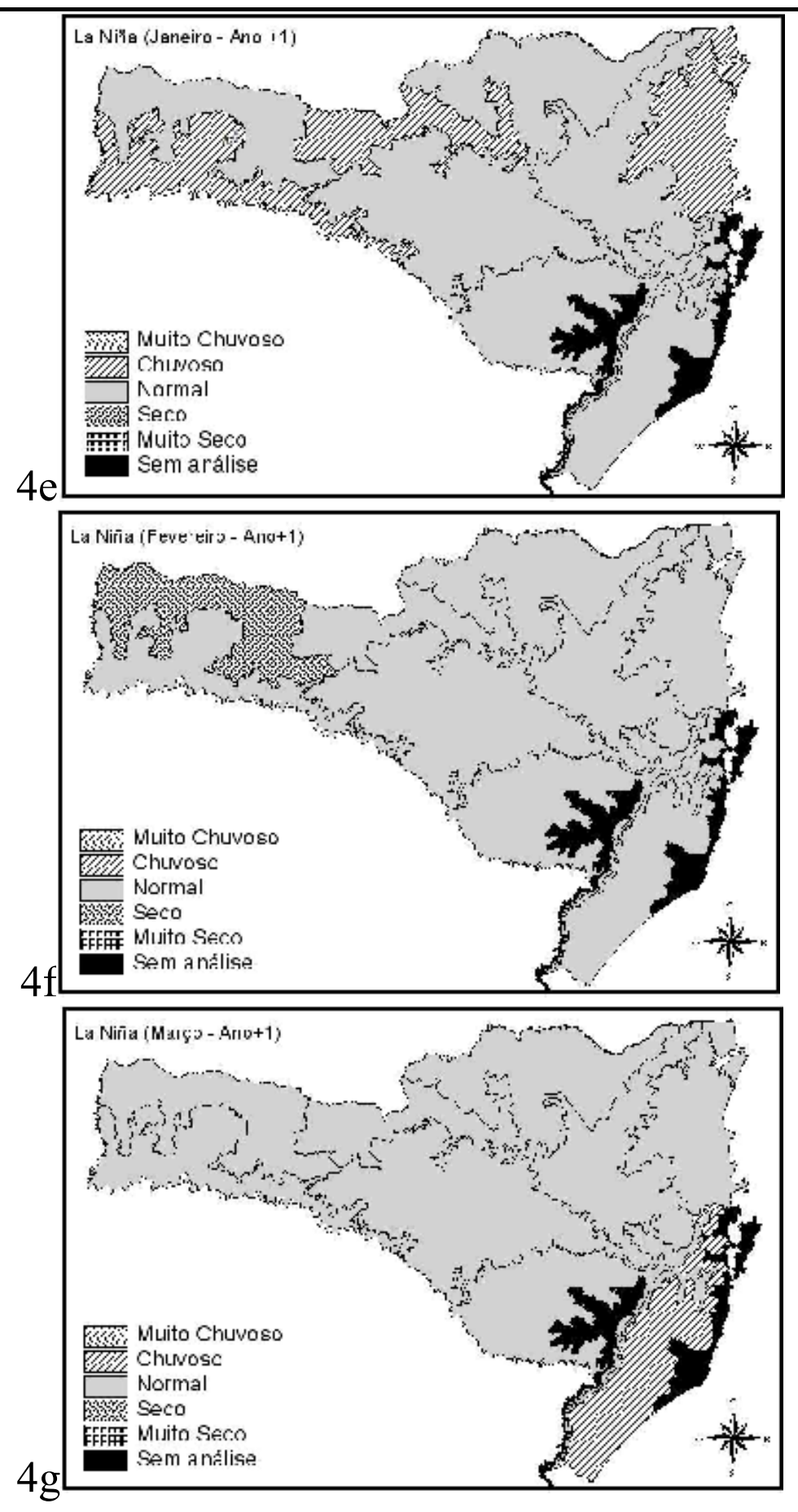

Geosul, v.25, n.50, 2010 
MINUZZI, R.B. Chuvas em Santa Catarina durante eventos do El Niño ...
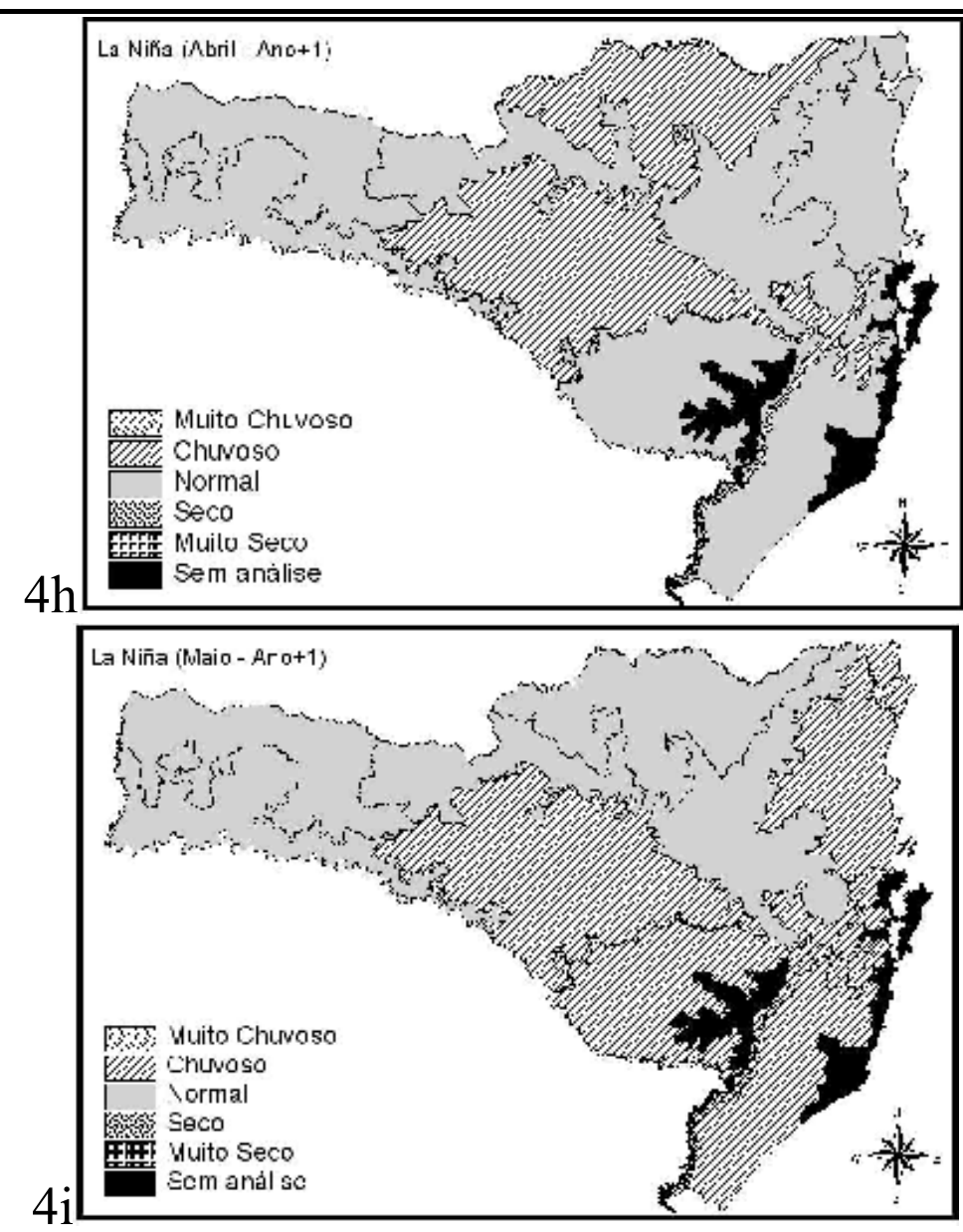

FIGURA 4: Classificações da chuva durante ocorrências da La Niña nos meses de setembro (4a), outubro (4b), novembro (4c), dezembro (4d), janeiro (4e), fevereiro (4f), março (4g), abril (4h) e maio (4i), em regiões climáticas de Santa Catarina.

É notável destacar que durante a atuação de ambas fases do ENOS, os meses com desvios mais significativos e abrangentes em Santa Catarina são novembro e maio, caracterizados com chuvas acima da climatologia, exceto em novembro, durante eventos da La Niña. Diante dos comportamentos distintos da anomalia de chuva no ano de início (ano 0) em relação ao ano seguinte $($ ano +1$)$ de ocorrência da La Niña, uma explicação para este comportamento baseado na análise sinótica torna-se mais árduo. 
MINUZZI, R.B. Chuvas em Santa Catarina durante eventos do El Niño ...

\section{Correlação da precipitação com a TSM}

Os valores destacados na Tabela 2 mostram a correlação da chuva de setembro a maio com a Temperatura da Superfície do Mar (TSM) nas regiões oceânicas onde caracterizam o ENOS. As precipitações de outubro, novembro, janeiro, abril e maio, foram as que tiveram o maior número de coeficientes de regressão significativas aos níveis de 1 ou 5\%. Estes meses condizem com o maior número de anomalias significativas de chuva obtidas nas regiões catarinenses durante o ENOS, como em novembro e maio (Figuras 3c, 3i, 4c e 4i). Assim, pode-se inferir que as oscilações no clima estão correlacionadas com eventos do ENOS de moderada e forte intensidades. Estes resultados são coerentes aos obtidos por Cardoso e Silva Dias (2004), que correlacionaram as anomalias trimestrais sazonais de TSM dos oceanos Atlântico e Pacífico com as precipitações sobre regiões homogêneas do Sul e Sudeste do Brasil. Tais autores observaram um padrão de correlação mais persistente sobre os oceanos, nos trimestres marçoabril-maio e setembro-outubro-novembro. Grimm et al. (1998) mostraram que existe uma relação consistente entre anomalias de precipitação da região Sul do Brasil com as fases do ENOS, mas chamam a atenção que no ano seguinte a eventos de El Niño, as anomalias de precipitação podem ser influenciadas pela TSM no sudoeste do oceano Atlântico. Não há uma defasagem (lag) predominante ou TSM de uma região Niño, com maior número de correlações significativas com a precipitação. Apenas as chuvas de outubro, novembro e maio mostram ter um número expressivo de correlações significativas com todas as regiões Niños. Numa análise mais abrangente na escala espacial, Coelho e Ambrizzi (2000) indicaram que a região Niño 3 parece ser a que exerce maior influência sobre os padrões de precipitação na América do Sul em anos do ENOS.

A análise dos sinais dos coeficientes de correlação nos meses com desvios mais significativos, mostram algumas contradições entre as tendências observadas nos volumes de chuva 
MINUZZI, R.B. Chuvas em Santa Catarina durante eventos do El Niño ...

com o comportamento característico da TSM durante as fases do ENOS. Como exemplos, em maio, os sinais positivos dos coeficientes significativos indicam que os volumes de chuva tendem a aumentar proporcionalmente com a TSM, o que seria pouco conveniente com a característica da La Niña (resfriamento da TSM), bem como, os coeficientes negativos de janeiro, sugerem que os volumes de chuva tendem a aumentar proporcionalmente com a diminuição da TSM, contrariando as características de aquecimento durante eventos El Niño, principalmente, por ser um mês em que normalmente a forçante climática atinge o seu auge. 
MINUZZI, R.B. Chuvas em Santa Catarina durante eventos do El Niño ...

TABELA 2: Coeficientes de Correlação de Pearson entre a chuva mensal das regiões climáticas de Santa Catarina e da TSM nas regiões Niños defasadas em até três meses.

\begin{tabular}{|c|c|c|c|c|c|c|c|c|c|c|c|c|}
\hline \multirow{3}{*}{$\overline{\text { Chuva JAN }}$} & \multicolumn{12}{|c|}{ Temperatura da Superfície do Mar (TSM) mensal } \\
\hline & \multicolumn{3}{|c|}{ Niño $1+2$} & \multicolumn{3}{|c|}{ Niño 3} & \multicolumn{3}{|c|}{ Niño 4} & \multicolumn{3}{|c|}{ Niño 3.4} \\
\hline & $\operatorname{dez}$ & nov & out & $\operatorname{dez}$ & nov & out & $\operatorname{dez}$ & nov & out & $\mathrm{dez}$ & nov & out \\
\hline & \multicolumn{12}{|c|}{ Correlação (Chuva mensal x TSM mensal) } \\
\hline $1 \mathrm{~A}$ & $-0,13$ & $-0,43^{*}$ & 0,04 & $-0,35$ & $-0,41 *$ & $-0,03$ & $-0,26$ & 0,17 & 0,05 & $-0,12$ & $-0,06$ & $-0,15$ \\
\hline $4 \mathrm{~A}$ & $-0,11$ & $-0,24$ & $0,44 *$ & $-0,02$ & $-0,01$ & 0,18 & 0,13 & $0,4^{*}$ & 0,34 & $-0,02$ & 0,24 & 0,31 \\
\hline $3 \mathrm{~A}$ & 0 & $-0,48 * *$ & 0,24 & $-0,23$ & $-0,32$ & $-0,01$ & $-0,33$ & $-0,08$ & $-0,24$ & $-0,26$ & 0,09 & $-0,22$ \\
\hline $2 \mathrm{~A}$ & $-0,15$ & $-0,67 * *$ & $-0,27$ & $-0,43^{*}$ & $-0,39 *$ & $-0,21$ & $-0,58 * *$ & $-0,08$ & $-0,24$ & $-0,37 *$ & $-0,19$ & $-0,4^{*}$ \\
\hline $4 B$ & $-0,21$ & 0 & 0,25 & 0,1 & 0,24 & 0,37 & $-0,02$ & 0,36 & 0,22 & 0,2 & 0,26 & 0,11 \\
\hline $3 \mathrm{C}$ & $-0,29$ & $-0,18$ & 0,24 & $-0,17$ & $-0,33$ & $-0,03$ & $-0,12$ & 0,22 & 0,06 & 0,12 & $-0,21$ & $-0,14$ \\
\hline $2 \mathrm{C}$ & $-0,15$ & $-0,44^{*}$ & 0,26 & $-0,26$ & $-0,42 *$ & $-0,04$ & $-0,2$ & $-0,06$ & $-0,2$ & $-0,11$ & $-0,18$ & $-0,35$ \\
\hline $3 \mathrm{~B}$ & $-0,13$ & $-0,62 * *$ & $-0,11$ & $-0,56 * *$ & $-0,3$ & $-0,03$ & $-0,48^{*}$ & $-0,26$ & $-0,26$ & $-0,37$ & $-0,26$ & $-0,38^{*}$ \\
\hline $2 \mathrm{~B}$ & $-0,21$ & $-0,33$ & $-0,06$ & $-0,27$ & $-0,47 *$ & 0,01 & 0,06 & $-0,07$ & $-0,04$ & $-0,09$ & 0,01 & 0,01 \\
\hline$\overline{\text { Chuva FEV }}$ & jan & $\mathrm{dez}$ & nov & jan & $\mathrm{dez}$ & nov & jan & $\operatorname{dez}$ & nov & jan & $\mathrm{dez}$ & nov \\
\hline $1 \mathrm{~A}$ & 0,02 & $-0,18$ & $-0,21$ & $-0,17$ & $-0,18$ & $-0,2$ & $-0,12$ & $-0,28$ & $-0,11$ & $-0,17$ & $-0,18$ & $-0,2$ \\
\hline $4 \mathrm{~A}$ & $-0,07$ & 0,15 & 0,15 & 0,05 & 0,1 & 0,06 & $-0,47^{*}$ & $-0,31$ & 0,03 & 0,05 & 0,1 & 0,06 \\
\hline $3 \mathrm{~A}$ & 0,26 & $0,39^{*}$ & 0,22 & $0,36^{*}$ & 0,34 & 0,26 & $-0,06$ & 0,04 & $0,38^{*}$ & $0,37 *$ & 0,34 & 0,26 \\
\hline $2 \mathrm{~A}$ & 0,01 & 0,12 & 0,1 & 0,12 & 0,15 & 0,09 & $-0,21$ & $-0,17$ & 0,09 & 0,12 & 0,14 & 0,09 \\
\hline $4 \mathrm{~B}$ & 0,18 & 0,1 & 0,03 & 0,32 & $0,37 *$ & $0,37 *$ & 0,1 & 0,26 & $0,59 * *$ & 0,32 & 0,37 & 0,37 \\
\hline $3 \mathrm{C}$ & 0,08 & 0,22 & 0,11 & 0,28 & 0,3 & 0,2 & 0,01 & 0,14 & 0,33 & 0,25 & 0,29 & 0,19 \\
\hline $2 \mathrm{C}$ & 0,25 & 0,3 & 0,23 & 0,29 & 0,31 & 0,25 & 0,14 & 0,23 & $0,46^{*}$ & 0,3 & 0,31 & 0,25 \\
\hline $3 \mathrm{~B}$ & $-0,18$ & $-0,15$ & $-0,26$ & $-0,35$ & $-0,32$ & $-0,4^{*}$ & $-0,02$ & $-0,16$ & 0,3 & $-0,35$ & $-0,32$ & $-0,4^{*}$ \\
\hline $2 \mathrm{~B}$ & $-0,23$ & $-0,13$ & $-0,32$ & $-0,24$ & $-0,14$ & $-0,21$ & $-0,08$ & $-0,12$ & $-0,1$ & $-0,24$ & $-0,14$ & $-0,21$ \\
\hline Chuva MAR & fev & $\mathrm{j}$ an & $\mathrm{dez}$ & fev & jan & $\operatorname{dez}$ & $\mathrm{fev}$ & jan & $\mathrm{dez}$ & fev & jan & $\operatorname{dez}$ \\
\hline $1 \mathrm{~A}$ & $-0,26$ & $-0,08$ & 0,19 & 0,24 & 0,18 & 0,17 & 0,16 & $-0,01$ & $-0,08$ & 0,24 & 0,18 & 0,16 \\
\hline $4 \mathrm{~A}$ & $-0,15$ & 0,33 & $-0,29$ & $-0,24$ & $-0,23$ & $-0,11$ & $-0,3$ & $-0,4 *$ & $-0,07$ & $-0,24$ & $-0,23$ & $-0,11$ \\
\hline $3 \mathrm{~A}$ & $-0,23$ & $-0,22$ & 0,09 & 0,19 & 0,16 & 0,22 & 0,07 & 0,11 & 0,16 & 0,19 & 0,16 & 0,22 \\
\hline $2 \mathrm{~A}$ & $-0,35^{*}$ & $-0,45^{*}$ & $-0,01$ & 0,12 & 0,08 & 0,14 & 0,17 & 0,01 & 0,05 & 0,12 & 0,08 & 0,14 \\
\hline $4 \mathrm{~B}$ & $0,45^{*}$ & $0,45^{*}$ & 0,33 & $0,46^{*}$ & $0,49^{*}$ & $0,44^{*}$ & 0,28 & 0,23 & 0,25 & $0,47^{*}$ & $0,49^{*}$ & $0,44^{*}$ \\
\hline $3 \mathrm{C}$ & $0,35^{*}$ & $0,41 *$ & $0,42 *$ & $0,52 * *$ & $0,49 *$ & $0,48 *$ & 0,27 & 0,22 & 0,24 & $0,52 * *$ & $0,49^{*}$ & $0,48^{*}$ \\
\hline $2 \mathrm{C}$ & 0,07 & 0,26 & 0,28 & 0,22 & 0,15 & 0,17 & 0,18 & 0,12 & 0,16 & 0,22 & 0,15 & 0,17 \\
\hline $3 \mathrm{~B}$ & 0,11 & $-0,04$ & $-0,04$ & 0,19 & 0,15 & 0,08 & 0,12 & $-0,01$ & $-0,19$ & 0,19 & 0,15 & 0,08 \\
\hline $2 \mathrm{~B}$ & $-0,35^{*}$ & $-0,43^{*}$ & $-0,15$ & $-0,01$ & $-0,04$ & 0,08 & $-0,11$ & 0,01 & 0,16 & 0,01 & $-0,03$ & 0,08 \\
\hline$\overline{\text { Chuva ABR }}$ & $\operatorname{mar}$ & fev & jan & mar & $\mathrm{fev}$ & jan & mar & $\mathrm{fev}$ & jan & mar & fev & jan \\
\hline $1 \mathrm{~A}$ & $-0,03$ & 0,2 & 0,35 & $-0,06$ & $-0,15$ & $-0,05$ & $-0,43^{*}$ & $-0,4^{*}$ & $-0,49^{*}$ & $-0,06$ & $-0,15$ & $-0,05$ \\
\hline $4 \mathrm{~A}$ & 0,19 & 0,2 & 0,14 & $-0,06$ & $-0,33$ & $-0,25$ & $-0,44^{*}$ & $-0,41 *$ & $-0,35$ & $-0,06$ & $-0,33$ & $-0,24$ \\
\hline $3 \mathrm{~A}$ & 0,25 & $0,43 *$ & 0,35 & 0,14 & 0,19 & $-0,15$ & $-0,33$ & $-0,31$ & $-0,54 * *$ & 0,14 & 0,19 & $-0,15$ \\
\hline $2 \mathrm{~A}$ & 0,28 & 0,33 & 0,25 & 0,13 & 0,01 & $-0,02$ & $-0,25$ & $-0,17$ & $-0,50 * *$ & 0,13 & 0,01 & 0,02 \\
\hline $4 \mathrm{~B}$ & 0,31 & $0,48^{* *}$ & $0,44 *$ & 0,36 & 0,01 & 0,08 & $-0,21$ & $-0,2$ & $-0,39 *$ & 0,36 & 0,01 & 0,08 \\
\hline $3 \mathrm{C}$ & 0,14 & 0,12 & $0,42 *$ & 0,07 & $-0,01$ & 0,16 & $-0,35$ & $-0,29$ & $-0,52 * *$ & 0,07 & $-0,01$ & 0,16 \\
\hline $2 \mathrm{C}$ & 0,1 & 0,13 & 0,26 & $-0,07$ & $-0,14$ & $-0,01$ & $-0,41^{*}$ & $-0,31$ & $-0,45^{*}$ & $-0,07$ & $-0,15$ & $-0,01$ \\
\hline $3 \mathrm{~B}$ & $-0,04$ & 0,15 & $0,44 *$ & $-0,03$ & $-0,08$ & 0,03 & $-0,3$ & $-0,28$ & $-0,36$ & $-0,03$ & $-0,08$ & 0,03 \\
\hline $2 \mathrm{~B}$ & $-0,12$ & 0,28 & 0,18 & 0,33 & 0,23 & 0,32 & 0,01 & 0,03 & 0,17 & 0,33 & 0,23 & 0,32 \\
\hline$\overline{\text { Chuva MAI }}$ & $a b r$ & $\operatorname{mar}$ & $\mathrm{fev}$ & $a b r$ & mar & fev & $a b r$ & mar & $\mathrm{fev}$ & $a b r$ & mar & fev \\
\hline $1 \mathrm{~A}$ & 0,22 & 0,09 & $-0,08$ & 0,28 & 0,33 & 0,3 & 0,37 & 0,37 & 0,27 & 0,28 & 0,33 & 0,29 \\
\hline $4 \mathrm{~A}$ & $0,39^{*}$ & 0,29 & 0,12 & $0,38^{*}$ & $0,38^{*}$ & 0,3 & $0,61 * *$ & $0,47^{*}$ & 0,37 & $0,38^{*}$ & $0,38^{*}$ & 0,29 \\
\hline $3 \mathrm{~A}$ & 0,21 & 0,25 & 0,09 & $0,39 *$ & $0,42 *$ & 0,36 & $0,55^{* *}$ & $0,46^{*}$ & 0,36 & $0,39^{*}$ & $0,42^{*}$ & 0,36 \\
\hline $2 \mathrm{~A}$ & $0,41^{*}$ & 0,17 & $-0,04$ & 0,3 & 0,3 & 0,28 & $0,46^{*}$ & 0,34 & 0,24 & 0,3 & 0,3 & 0,28 \\
\hline $4 \mathrm{~B}$ & 0,36 & 0,23 & 0,02 & $0,43^{*}$ & $0,41 *$ & 0,28 & $0,52 * *$ & 0,33 & 0,26 & $0,43^{*}$ & $0,41 *$ & 0,28 \\
\hline $3 \mathrm{C}$ & $0,38^{*}$ & 0,21 & 0,02 & 0,31 & 0,34 & 0,31 & 0,38 & 0,26 & 0,24 & 0,31 & 0,34 & 0,3 \\
\hline $2 \mathrm{C}$ & 0,26 & 0,24 & 0,01 & 0,28 & 0,32 & 0,29 & 0,36 & 0,26 & 0,24 & 0,28 & 0,32 & 0,28 \\
\hline $3 \mathrm{~B}$ & 0,33 & 0,06 & $-0,04$ & 0,35 & 0,34 & 0,2 & $0,46^{*}$ & 0,33 & 0,22 & $0,35^{*}$ & 0,34 & 0,22 \\
\hline $2 \mathrm{~B}$ & 0,2 & 0,14 & $-0,05$ & 0,17 & 0,12 & 0,08 & 0,2 & 0,15 & 0,06 & 0,17 & 0,12 & 0,07 \\
\hline
\end{tabular}


MINUZZI, R.B. Chuvas em Santa Catarina durante eventos do El Niño ...

\begin{tabular}{|c|c|c|c|c|c|c|c|c|c|c|c|c|}
\hline \multicolumn{13}{|c|}{ Tabela 2- continuação. } \\
\hline Chuva SET & ag o & jul & jun & $\operatorname{ag} 0$ & jul & jun & ago & jul & jun & ago & jul & jun \\
\hline $1 \mathrm{~A}$ & $-0,09$ & 0,2 & $-0,12$ & $0,47^{* *}$ & $0,4^{*}$ & 0,36 & $0,44^{*}$ & $0,47 *$ & 0,36 & $0,47^{*}$ & $0,4^{*}$ & 0,37 \\
\hline $4 \mathrm{~A}$ & $-0,12$ & 0,27 & $-0,09$ & 0,21 & 0,01 & 0,3 & 0,32 & $0,37 *$ & 0,37 * & 0,21 & 0,01 & 0,3 \\
\hline $3 \mathrm{~A}$ & $-0,13$ & 0,16 & $-0,15$ & 0,29 & 0,27 & 0,23 & 0,32 & 0,36 & 0,29 & 0,29 & 0,27 & 0,22 \\
\hline $2 \mathrm{~A}$ & 0,06 & 0,35 & 0,06 & 0,31 & 0,3 & 0,2 & 0,27 & 0,28 & 0,23 & 0,31 & 0,3 & 0,2 \\
\hline $4 \mathrm{~B}$ & 0,14 & 0,07 & 0,01 & 0,19 & 0,31 & 0,03 & 0,23 & 0,27 & 0,31 & 0,19 & 0,3 & 0,03 \\
\hline $3 \mathrm{C}$ & $0,38^{*}$ & 0,34 & $0,53 *$ & 0,11 & $0,45 *$ & $-0,02$ & 0,22 & 0,21 & 0,16 & 0,1 & $0,45^{*}$ & $-0,02$ \\
\hline $2 \mathrm{C}$ & 0,09 & $-0,06$ & $-0,01$ & $-0,01$ & 0,08 & $-0,14$ & $-0,03$ & 0,02 & 0,04 & $-0,01$ & 0,08 & $-0,14$ \\
\hline $3 \mathrm{~B}$ & 0,25 & 0,13 & 0,16 & 0,28 & $0,52 * *$ & 0,09 & $0,37 *$ & $0,39 *$ & $0,4 *$ & 0,28 & $0,52 * *$ & 0,09 \\
\hline $2 \mathrm{~B}$ & $-0,05$ & 0,31 & 0,09 & 0,2 & 0,01 & 0,31 & 0,11 & 0,2 & 0,09 & 0,2 & $-0,01$ & 0,31 \\
\hline$\overline{\text { Chuva OUT }}$ & set & ago & jul & set & ago & $\mathrm{jul}$ & set & ago & jul & set & ago & jul \\
\hline $1 \mathrm{~A}$ & 0,03 & $-0,08$ & $-0,01$ & $0,43^{*}$ & $0,4^{*}$ & 0,28 & $0,47^{*}$ & 0,33 & 0,15 & $0,43^{*}$ & $0,4^{*}$ & 0,28 \\
\hline $4 \mathrm{~A}$ & 0,25 & 0,06 & 0,31 & $0,53 * *$ & $0,55^{* *}$ & $0,45 * *$ & $0,54 * *$ & $0,47 *$ & 0,28 & $0,53^{* *}$ & $0,55 * *$ & $0,45^{*}$ \\
\hline $3 \mathrm{~A}$ & $-0,12$ & $-0,26$ & $-0,01$ & $0,39 *$ & $0,41 *$ & 0,28 & $0,39^{*}$ & 0,33 & 0,18 & $0,39^{*}$ & $0,41^{*}$ & 0,28 \\
\hline $2 \mathrm{~A}$ & 0,05 & $-0,11$ & 0,06 & $0,4 *$ & 0,36 & 0,23 & $0,4^{*}$ & 0,31 & 0,18 & $0,39 *$ & 0,36 & 0,23 \\
\hline $4 \mathrm{~B}$ & $-0,52 *$ & $-0,47 *$ & $-0,32$ & 0,18 & 0,17 & 0,11 & 0,3 & 0,19 & $-0,02$ & 0,18 & 0,17 & 0,11 \\
\hline $3 \mathrm{C}$ & $-0,48^{*}$ & $-0,46 *$ & $-0,54^{*}$ & 0,03 & 0,05 & $-0,15$ & 0,12 & $-0,03$ & $-0,25$ & 0,03 & $-0,05$ & $-0,15$ \\
\hline $2 \mathrm{C}$ & $-0,37$ & $-0,41 *$ & 0,01 & 0,14 & 0,11 & $-0,01$ & 0,29 & 0,14 & $-0,04$ & 0,15 & 0,11 & $-0,02$ \\
\hline $3 \mathrm{~B}$ & $-0,24$ & $-0,13$ & $-0,47 *$ & $-0,01$ & $-0,05$ & $-0,11$ & 0,01 & 0,03 & $-0,21$ & 0,08 & $-0,05$ & $-0,11$ \\
\hline $2 \mathrm{~B}$ & 0,26 & 0,05 & 0,35 & $0,41 *$ & $0,43 *$ & 0,34 & 0,41 * & 0,3 & 0,16 & $0,41^{*}$ & $0,43 *$ & 0,34 \\
\hline Chuva NOV & out & set & ago & out & set & ago & out & set & ago & out & set & $\operatorname{ag} 0$ \\
\hline $1 \mathrm{~A}$ & $0,45^{*}$ & $0,39^{*}$ & 0,25 & $0,46^{* *}$ & 0,29 & 0,21 & $0,48^{*}$ & 0,27 & 0,08 & $0,46^{*}$ & 0,29 & 0,21 \\
\hline $4 \mathrm{~A}$ & $0,52 * *$ & $0,52 * *$ & $0,39^{*}$ & $0,58 * *$ & $0,54 * *$ & $0,38^{*}$ & $0,5 * *$ & $0,44^{*}$ & 0,36 & $0,58^{* *}$ & $0,54 * *$ & $0,38^{*}$ \\
\hline $3 \mathrm{~A}$ & $0,5^{*}$ & $0,46^{*}$ & 0,3 & $0,6 * *$ & $0,5 * *$ & $0,42 *$ & $0,54 * *$ & $0,49^{*}$ & $0,4 *$ & $0,6^{* *}$ & $0,5 *$ & $0,42^{*}$ \\
\hline $2 \mathrm{~A}$ & $0,44^{*}$ & 0,32 & 0,25 & $0,53 * *$ & $0,5^{* *}$ & $0,37 *$ & $0,53 * *$ & 0,47 * & 0,31 & $0,53 * *$ & $0,5 *$ & $0,37^{*}$ \\
\hline $4 \mathrm{~B}$ & 0,34 & 0,15 & 0,04 & $0,43 *$ & 0,34 & 0,31 & 0,34 & 0,33 & 0,29 & $0,43^{*}$ & 0,34 & 0,31 \\
\hline $3 \mathrm{C}$ & $0,49 *$ & 0,35 & 0,16 & $0,51 * *$ & $0,4^{*}$ & 0,36 & $0,45^{*}$ & $0,44 *$ & 0,31 & $0,51 *$ & 0,4 * & $0,37^{*}$ \\
\hline $2 \mathrm{C}$ & $0,57 * *$ & $0,44 *$ & 0,22 & $0,6 * *$ & $0,54 * *$ & $0,46 * *$ & $0,52 * *$ & $0,55 * *$ & $0,46^{*}$ & $0,6^{* *}$ & $0,54 * *$ & $0,46^{*}$ \\
\hline $3 \mathrm{~B}$ & $0,42 *$ & 0,37 & 0,14 & $0,46 * *$ & $0,4 *$ & 0,33 & $0,43^{*}$ & $0,39 *$ & 0,23 & $0,45^{*}$ & $0,4 *$ & 0,33 \\
\hline $2 \mathrm{~B}$ & 0,31 & $0,39 *$ & $0,48 *$ & $0,39 *$ & 0,36 & $0,37 *$ & $0,4 *$ & 0,3 & 0,26 & $0,39 *$ & 0,36 & $0,37 *$ \\
\hline$\overline{\text { Chuva DEZ }}$ & nov & out & set & nov & out & set & nov & out & set & nov & out & s et \\
\hline $1 \mathrm{~A}$ & 0,23 & 0,36 & 0,33 & 0,01 & 0,08 & 0,15 & 0,37 & 0,17 & 0,14 & 0,01 & 0,09 & 0,15 \\
\hline $4 \mathrm{~A}$ & $-0,12$ & 0,02 & 0,06 & $-0,02$ & 0,01 & 0,01 & $-0,23$ & $-0,24$ & $-0,24$ & $-0,02$ & 0,02 & $-0,01$ \\
\hline $3 \mathrm{~A}$ & $-0,03$ & $-0,19$ & $-0,19$ & $-0,29$ & $-0,15$ & 0,23 & 0,21 & $-0,21$ & $-0,12$ & $-0,29$ & $-0,15$ & $-0,23$ \\
\hline $2 \mathrm{~A}$ & 0,03 & 0,06 & $-0,03$ & $-0,05$ & 0,01 & 0,04 & 0,04 & 0,04 & 0,04 & $-0,05$ & 0,01 & 0,04 \\
\hline $4 \mathrm{~B}$ & $-0,07$ & $-0,11$ & $-0,17$ & 0,08 & 0,13 & $-0,03$ & $-0,08$ & 0,06 & 0,01 & 0,07 & 0,13 & $-0,03$ \\
\hline $3 \mathrm{C}$ & 0,06 & $-0,28$ & $-0,32$ & 0,09 & 0,25 & 0,11 & $-0,03$ & 0,21 & 0,16 & 0,09 & 0,25 & 0,11 \\
\hline $2 \mathrm{C}$ & 0,01 & $-0,03$ & $-0,08$ & 0,16 & 0,18 & 0,11 & 0,07 & 0,16 & 0,14 & 0,16 & 0,18 & 0,11 \\
\hline $3 \mathrm{~B}$ & 0,07 & 0,04 & 0,02 & 0,01 & 0,05 & $-0,02$ & $-0,04$ & $-0,09$ & $-0,11$ & $-0,01$ & 0,05 & $-0,02$ \\
\hline $2 \mathrm{~B}$ & $-0,07$ & $-0,09$ & $-0,05$ & $-0,03$ & 0,1 & $-0,27$ & $-0,08$ & $-0,46^{*}$ & $-0,29$ & $-0,03$ & 0,1 & $-0,27$ \\
\hline
\end{tabular}

\section{Conclusões}

-Em anos de El Niño as chuvas de setembro ficam abaixo da média climática no Litoral de Santa Catarina. Em contrapartida, em novembro, no verão e o mês de maio, tendem a ser períodos 'chuvosos'. 
MINUZZI, R.B. Chuvas em Santa Catarina durante eventos do El Niño ...

-Durante eventos La Niña, os volumes de chuva em outubro e novembro ficam abaixo da média, ocorrendo comportamento oposto, em abril e maio.

-As chuvas dos meses com o maior número de desvios obtidos nas regiões do Estado (novembro e maio), estão relacionados com o comportamento da TSM nas regiões Niños.

\section{Referências bibliográficas}

BRAGA, H.J.; GHELLRE, R. Proposta de diferenciação climática para o Estado de Santa Catarina. In: CONGRESSO BRASILEIRO DE AGROMETEOROLOGIA, 11 E REUNIÃO LATINOAMERICANA DE AGROMETEOROLOGIA, 2, 1999, Florianópolis. Anais... Florianópolis: SBAgro, 1999. CD-Rom.

CARDOSO, A.O.; SILVA DIAS, P.L. Identificação de trimestres extremos no regime pluviométrico do Sul e Sudeste do Brasil e relação com anomalias da TSM. Revista Brasileira de Meteorologia, v.19, n.2, SBMet, p.149-162. 2004.

CAYAN, D.R.; REDMOND, K.T.; RIDDLE, L.G. ENOS and hydrologic extremes in Western United States. Journal of Climate, Boston, v.12, p.2881-2893, 1999.

CHATFIELD, C. Wet and dry spells. Monthly Weather Review, Boston, v.21, p.308-310, 1966.

COELHO, C.A.S.; AMBRIZZI T. Determinação dos padrões de precipitação sobre a América do Sul em associação com a TSM da Bacia do pacífico equatorial durante períodos extremos de ENOS através da utilização de técnicas estatísticas multivariadas. In: CONGRESSO BRASILEIRO DE METEOROLOGIA, 11, 2000, Rio de Janeiro. Anais... Rio de Janeiro: SBMET, 2000. CD-Rom. 
MINUZZI, R.B. Chuvas em Santa Catarina durante eventos do El Niño ...

FEDOROVA, N.; LEVIT, V.; CARVALHO, M.H. de. Eventos de precipitação na cidade de Pelotas-RS associados a processos e sistemas sinóticos. Revista Brasileira de Meteorologia, v.22, n.2, p.134-160, 2007.

GERSHUNOV, A.; BARNETT, T.P. ENOS influence on intraseasonal extreme rainfall and temperature frequencies in the contiguous United States: Observations and Model Results. Journal of Climate, v.11, p.1575-1586, 1998.

GRIMM, A.M. Variabilidade interanual do clima no Brasil. In: Tempo e clima no Brasil. Cavalcanti et al. [organizadores]. São Paulo: Oficina de Textos, 463p. 2009.

GRIMM, A.M.; TEDESCHI, R.G. Influência de eventos El Niño e La Niña sobre a frequência de eventos extremos de precipitação no Brasil. In: CONGRESSO BRASILEIRO DE METEOROLOGIA, 13, 2004, Fortaleza. Anais... Fortaleza, CE: SBMet, 2004. CDRom.

GRIMM, A.M.; FERRAZ, S.E.T. Sudeste do Brasil: uma região de transição no impacto de eventos extremos da Oscilação Sul. Parte II: La Niña. In: CONGRESSO BRASILEIRO DE METEOROLOGIA, 10, 1998, Brasília. Anais... Brasília, DF: SBMet, 1998. CD-Rom.

GRIMM, A.M.; FERRAZ, S.E.T.; GOMES, J. Precipitation anomalies in Southern Brazil associated with El Niño and La Niña events. Journal fo Climate, Boston, v.11, p.2836-2880, 1998.

IRI. Disponível em 'Air-Sea Interface Data in the IRI Library: $<$ http://iridl.ldeo.columbia.edu/docfind/databrief/cat-airsea.html $>$. Acesso em: 2008. 
MINUZZI, R.B. Chuvas em Santa Catarina durante eventos do El Niño ...

MANSON, S.J.; GODDARD, L. Probabilistic precipitation anomalies associated with ENSO. Bulletim of the American Meteorological Society, Washington, v.82, n.4, p.619-638, 2001.

MARENGO, J.A.; SOARES, W.R.; SAULO, C.; NICOLINI, M. Climatology of the Low-Level Jet east of the Andes as derived from the NCEP reanalyses. Journal of Climate, Boston, v.17, p.2261-2280, 2004.

OLIVEIRA, G.S. de. El Niño e você: o fenômeno climático. São José dos Campos, SP: TRANSTEC, 1999, 116p.

SILVA, G.A.M. Variabilidade Inter-El Niños e seu impacto no Jato de Baixos Níveis a leste dos Andes durante o verão austral. São Paulo, SP: USP, 2005. 84p. Dissertação (Mestrado) Universidade de São Paulo, São Paulo.

TRENBERTH, K.E. The definition of El Niño. Bulletim of the American Meteorological Society, Washington, v.78, n.12, p.2771-2777, 1997.

XAVIER, T.de M.B.S. Tempo de Chuva - Estudos Climáticos e de Previsão para o Ceará e Nordeste Setentrional. Fortaleza, CE: ABC Editora, 478p. 2001.

WILKS, D.S. Statistical methods in the atmospheric sciences. San Diego, Califórnia: Elsevier Inc. (2 ed.), 2006, 627p.

Recebido em abril de 2010 Aceito em março de 2011 
